\title{
Morphological Awareness and Vocabulary Knowledge
}

\author{
Ahmed Zrig
}

Department of English, Carthage University, Tunisia

\begin{abstract}
This study examined the relationship between the types of vocabulary knowledge (receptive and productive) and morphological awareness in an EFL context. The participants in this study were 60 fourth year secondary school Arts students in Ain Drahem, Tunisia. Students were grouped into two groups (control/ experimental) in order to check the effectiveness of teaching morphology on vocabulary knowledge. Vocabulary size was tested using adapted versions of vocabulary tests, namely Nation's (2001) Vocabulary Levels Test as a receptive measure of vocabulary size and Laufer and Nation's (1999) productive version of the Vocabulary Levels Test. The tests were modified by increasing the total number of test items to make them more representative of the 2000 and 3000-word frequency levels. Students' morphological awareness was measured by the Morphological Awareness Test with its four subsets (roots, derivational morphemes, compounds and inflectional morphemes).The VLT results showed that students' receptive size was larger than their productive size. Results revealed also that students performed better at the 2000-word frequency level than at the 3000-word level. Besides, the informants'scores were high on the overall morphological awareness task, and the best performance was on inflectional morphemes for both groups. As predicted, morphological awareness was positively related to both receptive and productive vocabulary.
\end{abstract}

Keywords- Morphological awareness, productive vocabulary, receptive vocabulary, vocabulary knowledge, word frequency .

\section{INTRODUCTION}

Vocabulary knowledge is a language component necessary for fluent language use (Nation, 1993). In other words, vocabulary size is an indicator of how well second or foreign language learners perform academic language skills such as reading, listening, writing and speaking (Bear, Invernizz, Templeton and Johnson 2008). Having inadequate vocabulary knowledge may even hamper learners' discourse comprehension (Ellis, 1997). So, vocabulary teaching and learning is a crucial activity in any language class. In order to better understand the properties of vocabulary knowledge (hereafter VK), researchers are focusing on both a) how many words learners know (i.e., breadth of vocabulary knowledge), which is indicated by their knowledge of forms and meanings of lexical items; and b) how well learners know particular words (i.e., depth), which entails various receptive and productive subcomponents of word knowledge. Vocabulary learning can be enhanced by making use of some learning strategies. These strategies are consciously or unconsciously learned by students to process information and enhance comprehension, learning and retention (O'Malley and Chamot, 1990). One of these strategies is employing morphological awareness to learn new lexical items.

Morphological awareness (hereafter MA) is defined as "the ability to use the knowledge of word formation rules and the pairing between sounds and meanings" (Kuo \& Anderson, 2006). By the use of morphological awareness, students are able to learn morphemes and morphemic boundaries by disassembling complex words into smaller meaningful parts. The practice of dissemblingreassembling words is called morphological analysis. Morphological awareness has gained a snowballing interest as a crucial strategy of vocabulary knowledge, mainly in reading. For instance, Singson, Mahony and Mann (2000) argued that morphemes have phonological, semantic and syntactic properties that communicate the function of a specific word in the reading context (e.g. $-\mathrm{S}$ in the verb drives reveals that the doer of the action is only one person. and the action takes place in the present tense). In addition, morphological awareness enhances the 
learner's awareness of the writing system (Kuo and Anderson, 2006). That is to say, morphological knowledge helps learners to perceive better spelling and phonological irregularities (e.g. sign- signature). Studies show that language learners encounter complex words at early stages of their learning (Gordon, 1989; Carlisle and Stone, 2003). The fact that students encounter many derived words in their reading has motivated researchers to explore further the contribution of morphological awareness in vocabulary improvement. Despite the importance of morphological awareness in the development of learners' vocabulary knowledge, together with literacy-related skills (e.g., reading and spelling) (Wang, Cheng, \& Chen, 2006), little research has really investigated the relationship between breadth and depth of VK in relation to MA. In other words, more work is needed to be carried out to identify the relationship between both receptive and productive VK and different aspects of MA, and in particular, the nature of this relationship in foreign language learning.

\subsection{Question of the Study}

1. Do receptive and productive vocabulary sizes differ across frequency levels among Tunisian fourth year secondary school learners of English?

2. Are measures of morphological awareness related to measures of English receptive and productive vocabulary sizes before the treatment for the whole group and after the treatment for the control and the experimental group?

\section{METHOD}

\subsection{Informants}

The participants in this study were Tunisian fourth year secondary school students in Ain Drahem. Two groups of 30 students each, representing two entire classes (intact groups), have participated in the study (Baccalaureate of Arts).

\subsection{Instruments}

To answer the present research's questions two widely used tests were adapted to the purposes of the study: A Vocabulary Level Test with 2 subsets (receptive and productive) and a Morphological Awareness Test with its 2 subsets (morpheme identification and morphological structure). Besides, a questionnaire was created to provide a cross-check between what the test results show and the participants' ideas and attitudes towards the different testing instruments. Two vocabulary tasks have been used, namely Nation's Vocabulary Levels Test as a receptive measure of vocabulary size and Laufer and Nation's (1999) productive version of the Vocabulary Levels Test (PVLT). Both tests were adapted for the purpose of this study. The learners' morphological knowledge was tested by the Morphological Awareness Test (Chang et al. 2005). This test consists of two parts: a morpheme identification awareness test and a morphological structural awareness test. There is an important change made to the two tests in this present study. The test items in this study are in a written form, not oral as in Chang et al. (2005). The main reason behind this change is the practicality in administering the test. Finally, the questionnaire was self created to investigate the participants' attitudes towards their English vocabulary knowledge and morphological awareness, as well as their reactions to the different testing instruments.

\subsection{Design and Analysis}

This study used a "mixed design". In other words, sometimes a "between group design" was used to make comparisons between independent groups (control and experimental group). Some other times, a "within subjects design" was used to compare data from the same students (pre- and post-test). The tests have been administered over two days to minimize fatigue. The first day of testing consisted of the VLTs. The second day of testing included the morphological awareness test. Once all of the informants (control and experimental groups) have finished with this first step which is mainly aimed to answer the first research question, the researcher systematically selected half of the participants ( a group of 30 students) and introduced them to morphological awareness as a strategy of vocabulary acquisition (class instruction). Students of this study have little knowledge about morphemes. Also, they have never attended a class on morphology. During the two-week treatment period (4 separate hours per week), the experimental group received explicit instruction on inflectional and derivational morphemes etc. One month after the end of the treatment period, a post-test (same test as the pre-test with the items scrambled) was administered to both groups in order to investigate the second research question. In order to answer the first research question and highlight the differences in the vocabulary knowledge that were employed by each group of participants, the results of all the participants and the separate results of each group (control and experimental) were compared through TwoWay ANOVA. As the data in this study is quantitative; it allows performing various arithmetic operations to find statistics of the sample, and since the aim is to compare students' performance on the dependent and independent variables, the mean and standard deviation have been used to provide more details about research question 1 , which investigates the participants' receptive and productive vocabulary size, the results of the VLTs were summarized 
by means and standard deviations across the two different levels $(2,000$ and 3,000) to make the comparison possible.

As far as the second research question about students' morphological awareness is concerned, the whole group's results (60 students) were reported at the beginning of the analysis for two reasons. First, results helped to have a general overview of students' performance on the different subtests of the morphological awareness test and to check possible differences between students' performances at these tasks. Since this study used a pre-test post-test nonequivalent group design: matched pair t-tests were used to compare groups' performance on two conditions (before treatment/ after treatment). After these tests, a factorial Two-Way AVOVA was carried out with repeatedmeasures variable (Morpheme Type: roots, derivational, inflectional and compounds) and one between- subjects (Group: experimental group and control group) to check the performances of the two groups on the morphological awareness pre-tests and post-tests. Finally, independent measures t-tests were also used to compare performance of the two groups (experimental/ control) in more detail. The results of the morphological awareness test were also analyzed through the mean and standard deviation, in order to compare the participants' performances on different parts (roots, inflectional morphemes, compounds and derivational morphemes) of the test. In light of research question 2, Pearson's product-moment correlation was used to investigate the correlations between each of the Vocabulary Level Tests (receptive and productive) total scores and Morphological Awareness Test. First, scores of all participants were tested for correlation between these variables before the treatment. In conclusion, at the end of the vocabulary and morphology tests, students were asked to complete a questionnaire. The answers to the questionnaire were analyzed to investigate the

informants' perception of the different tests as well as their interest in applying morphological awareness raising as a strategy for their future English vocabulary learning.

\section{RESULTS AND DISCUSSION}

\subsection{Vocabulary size on receptive and productive vocabulary tests}

It is obvious from Table 1 that the students' performance on the receptive vocabulary test was better than their performance on the productive vocabulary test at both frequency levels. In addition, the participants' performances were highest at the 2,000-word level especially on the receptive tasks as manifested by the mean score 38. 05.

ISSN: 2456-7620
Table1. Means and standard deviations for scores on the $R V T$ and $P V T(N=60)$

\begin{tabular}{|c|c|c|c|c|}
\hline & \multicolumn{2}{|c|}{$\begin{array}{c}\text { Receptive } \\
\text { Vocabulary } \\
\text { Test }\end{array}$} & \multicolumn{2}{c|}{$\begin{array}{c}\text { Productive } \\
\text { Vocabulary } \\
\text { Test }\end{array}$} \\
\hline Frequency levels & Mean & SD & Mean & SD \\
\hline 2000 Word Level & 38.05 & 6.41 & 21.05 & 4.88 \\
\hline 3000 Word Level & 27.46 & 7.72 & 15.73 & 5.36 \\
\hline
\end{tabular}

Note: A maximum score at each frequency level is 50 for the RVT and 30 for PVT

Furthermore, it is worth mentioning that the gap between students' performances on the receptive and productive vocabulary tests was wider at the 2,000-word level where the percentages of both types of vocabulary size were significantly high $(76.1 \%$ and $70.16 \%)$. The percentage increased with dropping the frequency levels $(54.92 \%$ and $52.43 \%$ ). This can best be viewed in Fig.1. In fact, these findings are supported by Webb (2008) and Hayashy and Murphy (2009). Also, this figure shows that, as students' scores on the receptive test decreased between the two frequency levels, scores on the productive test decreased as well, which illustrates a positive relationship between receptive and productive vocabulary sizes. As additional comments, students wrote that the 3,000-word level in both tests (receptive / productive) was more difficult than the 2,000-word level. So, students' perception of tests difficulties was in line with their performance.

The first research question is concerned with the students' vocabulary size, as reflected in their performance on the vocabulary tests. The vocabulary size scores aimed to highlight the students' vocabulary proficiency after studying English for almost 7 years. The scores indicate that at the 2,000-word level, the average student among the participants in this study only masters about 1522 English words, of which they can only use about 1403 productively. Besides, at the 3,000-word level, the average student masters about 1647 English words, of which they can only use about 1572 productively. This finding is based on Zimmerman's (2005) claim that scores on the vocabulary test can be employed to give an estimate of the vocabulary size.

Compared to other studies, results indicate a better performance than those of (Taghipour 1999; Masumeh \& Omid, 2011), who found that the average first year Iranian university students master about 1040 and 1200 words respectively at the 2,000-word receptive vocabulary test. To put it another way, Iranian students obtained the correct score of $52 \%$ and $60 \%$ compared to $76.1 \%$ in this study. 
The conclusion that students of the current study performed better is based on the considerations that participants of the previously mentioned Iranian studies have also studied English for seven years and were tested by the same vocabulary testing instruments (Nation, 2001). Interestingly, Nagy and Anderson (1984) stated that there has been a lack of agreement among the researchers about an exact vocabulary size for any given age or development level.

Results of the Two-Way ANOVA revealed that word frequency had a main effect, $F(1,236)=10.17, p<.05$. The participants performed better at the 2,000-word level than the 3,000-word level on both the receptive and the productive vocabulary tests. It is worth mentioning that the difference in scores between the 2,000 and the 3,000word level reached a statistical significance $\mathrm{t}(59)=8.15, p$ $<0.5$ at the receptive test with a mean difference $(\mathrm{MD}=$ 10.57), and $\mathrm{t}(59)=5.67, p<0.5$ at the productive test with $(\mathrm{MD}=5.32)$. By conventional criteria, the difference is considered to be extremely statistically significant. This means, the participants' performance drastically dropped when increasing the frequency level.

Besides, there was a main effect of test type, $F(1,236)=$ $4.27, p<.05$, and a significant Test type $\times$ Frequency level interaction $F(1,236)=32.46, p<.05$. Results show that the difference between the participants' total scores on the RVT and PVT reached statistical significance, suggesting that their receptive vocabulary size is significantly larger than their productive vocabulary size. So, the null hypothesis can be rejected in this case because the $F$ value of 4.27 exceeds the critical value ( $F$ critical) of 2.00 needed for a probability level of 0.5 .

\subsection{The groups' performances on the vocabulary level pre-tests}

Table 2 shows that mean scores of both the control and the experimental group at the vocabulary pretests were close to each other at the different frequency levels, with an insignificant better performance for the control group in the 3,000-word receptive vocabulary test and another better performance for the experimental group in the 3,000-word productive vocabulary test.
Table 2: The groups' performances on the vocabulary level pre-tests

\begin{tabular}{|c|c|c|c|c|}
\hline Groups & \multicolumn{2}{|c|}{$\begin{array}{l}\text { Control } \\
(N=30)\end{array}$} & \multicolumn{2}{|c|}{$\begin{array}{c}\text { Experimental } \\
(N=30)\end{array}$} \\
\hline VLTs & Mean & $S D$ & Mean & $S D$ \\
\hline RVT 2000 & 38.03 & 6.71 & 38.06 & 6.20 \\
\hline RVT 3000 & 28 & 8.96 & 26.83 & 6.42 \\
\hline PVT 2000 & 21.23 & 5.96 & 20.86 & 3.58 \\
\hline PVT 3000 & 14.96 & 6.18 & 16.50 & 4.37 \\
\hline
\end{tabular}

Note: A maximum score at each frequency level is 50 for the RVT and 30 for PVT

In spite of these differences, the groups' overall performances were almost the same, indicating that the two groups were almost initially equivalent before the experiment as indicated below.

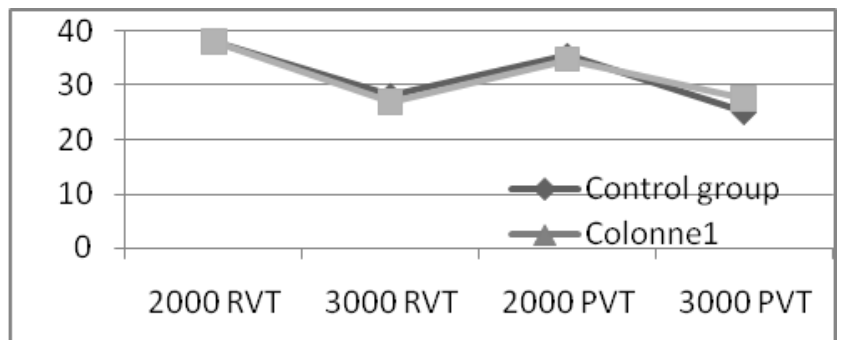

Fig. 1: Line charts showing groups' mean scores on the pre-test

Fig.1 shows that the experimental group was not initially better than the control group as demonstrated by their scores on the pre-test. So, the groups' performances overlap greatly. It is obvious that this is a case of disordinal interaction, as the lines representing performances of both groups intersect. Most importantly, is the fact that these two lines go in the same direction asserting that, both groups performed best at the 2,000word receptive level.

The RVT data were analyzed using a factorial analysis of variance (Two-Way ANOVA) with one repeated-measures variable (Frequency level: 2,000-word, 3,000-word levels), and one between- subjects variable (Group: experimental and control). A main effect of frequency level was observed, $F(1,116)=8.64 p<0.5$, suggesting that the two groups performed better at the 2,000-word level. However, the obtained $F$ ratio was not sufficiently larger than the critical value of $F$ to confirm the existence of a difference between groups $F(1,116)=1.43, p>0.5$ and the $F$ 
critical value is 3.80. This means that, there was no significant difference between groups' performances on the receptive vocabulary level pre-test. Furthermore, there was no significant Group $\times$ Frequency level interaction $F$ $(1,116)=3.67, p>0.5$.

Table3: The groups' performances on the vocabulary level post-tests

\begin{tabular}{|l|c|c|c|c|}
\hline \multirow{2}{*}{ VLTs } & \multicolumn{2}{c|}{$\begin{array}{c}\text { Control } \\
(\text { N=30 })\end{array}$} & \multicolumn{2}{c|}{$\begin{array}{c}\text { Experimental } \\
(\text { N=30 })\end{array}$} \\
\cline { 2 - 5 } & Mean & SD & Mean & SD \\
\hline RVT 2000 & 39 & 6.28 & 41.86 & 5.91 \\
\hline RVT 3000 & 27.32 & 9.01 & 31.80 & 7.24 \\
\hline PVT 2000 & 22.01 & 5.6 & 23 & 5.36 \\
\hline
\end{tabular}

Note: A maximum score at each frequency level is 50 for the RVT and 30 for PVT

There are three noticeable facts in this table. First, the participants' scores were higher at the 2,000-word levels than the 3,000-word levels, which means that scores dropped when decreasing the frequency level. Second, figures clearly reveal that the experimental group's scores were higher than those of the control group at both frequency levels (see Fig.2). This can be explained by the presence of the treatment for the experimental group.

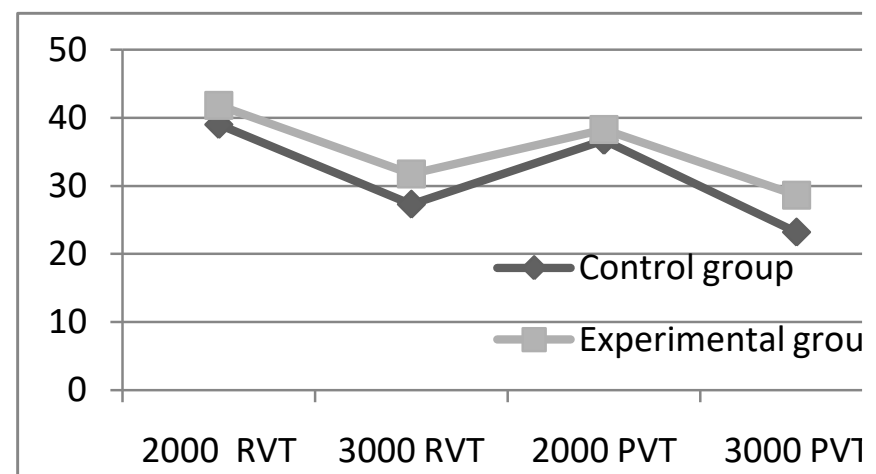

Fig. 2: Line charts showing groups' mean scores on the post-test

The RVT data were analyzed using a factorial analysis of variance (Two-Way ANOVA) with one repeated-measures variable (Frequency level: 2,000-word, 3,000-word levels), and one between- subjects variable (Group: experimental and control). A main effect of frequency level was observed, $F(1,116)=8.06 p<0.5$, suggesting that the two groups performed better at the 2,000-word level. Also, there was a main group effect, $F(1,116)=4.68 p<0.5$.
This means that, there was a significant difference between groups' performances on the receptive vocabulary level post-test In addition, there was a significant Group $\times$ Frequency level interaction, $F(1,116)=41.94, p<0.5$. Consequently, we can conclude confidently that the treatment did show a difference. In other words, the experimental group scores differ significantly from the control group scores on the receptive vocabulary posttests.

When checking the performances of the two groups on the PVT, a main effect of frequency level was observed, $F$ ( 1 , 116) $=5.14 p<0.5$. This suggests that the two groups performed better at the 2,000-word level. Also, there was a main group effect, $F(1,116)=6.97 p<0.5$, suggesting there was a significant difference between groups' performances on the productive vocabulary level post-test. Finally, there was a significant Group $\times$ Frequency level interaction, $F(1,116)=42.37, p<0.5$. The critical value of $F$ for both group and frequency level is 3.80. The obtained $F$ values exceeded this $F$ critical value. So, we can have confidence in concluding that the treatment did show a difference. In other words, the experimental group scores differ significantly from the control group scores on the productive vocabulary post-tests.

In conclusion, the factorial ANOVA tests between groups (experimental and control), and within groups (pretest and posttest) revealed significant differences on the vocabulary measures that are most likely due to the treatment. In fact, this goes with the perception of the effect of teaching morphology on students' performance in vocabulary tests (Hayashy \& Murphy, 2009). These results support an expansion of a morphology program for two reasons. First, morphology affects vocabulary, and vocabulary knowledge reflects reading comprehension (Snow, Burns and Griffin, 1998) and general academic achievement (Beck, Mc Keown and Kucan, 2002). Second, secondary school students are faced with a huge amount of readings in English that contains many complex words (Graves, 2004), which may not be necessarily the case for Tunisia of course. Nonetheless, the students should be equipped with some strategies to unlock the meanings of newly encountered words, and morphological awareness can be one of these strategies. Actually, students stated in the questionnaire that their teachers explained the new vocabulary synonyms, antonyms or examples but never through generating morphemes to new contexts. The participants expressed their willingness to use the morphological awareness techniques used during the training sessions. 


\subsection{Performance on the Morphological Awareness Tests}

As stated previously, the morphological awareness tasks were analyzed using first matched pair t-tests in order to compare the control and the experimental group separately on two conditions (pretest/ posttest), and then independent measures t-tests to compare performance of the two groups (experimental/ control). Besides, the results of the morphological awareness test were also analyzed through the mean and standard deviation, in order to provide more details about the participants' performances on different parts (roots, inflectional morphemes, compounds and derivational morphemes) of the test.

As stated in the method, the whole group's results (60 students) were reported to get first a general overview of students' performance on the different subtests of the morphological awareness test, and to be correlated latter with results from the VLT to answer the second research question. The difference between students' performance on the different parts of the morphological awareness test was insignificant as Table 4 shows.

Table 4: Mean and standard deviation for the morphological awareness subtests $(N=60)$

\begin{tabular}{|l|c|c|}
\hline Morphological Awareness Test & Mean & SD \\
\hline Root words test & 7.48 & 1.42 \\
\hline Derivational morphemes test & 7.78 & 1.59 \\
\hline Compound words test & 7.82 & 1.57 \\
\hline Inflectional morphemes test & 8.18 & 1.65 \\
\hline
\end{tabular}

Note: A maximum score at each morphological awareness subtest is 10

Students' scores at the different morphological awareness tasks were higher than 7 out of 10 , exept scores at inflectional morphemes which were slightly higher than 8 out of 10. That is to say, the results on the different morphology tests were the same with insignificant differences between them. In addition, the standard deviations of the different morphological awareness subtests varied very little, which means that students' scores were rather homogeneous. In line with the vocabulary language test, it was of crucial importance to make an intra-group comparison (repeated-measure) for the morphological awareness test. In other words, it was necessary to compare the control group's performances on the pre- and post-test as well as those of the experimental group to check the effectiveness of the instructional treatment.
3.4. The control group performances on the pre and post morphology tests

Table 5: The control group performances on the pre and post morphology tests $(N=30)$

\begin{tabular}{|l|l|c|c|c|}
\hline \multicolumn{1}{|c|}{ Test type } & \multicolumn{2}{c|}{ Pre Test } & \multicolumn{2}{c|}{ Post Test } \\
\cline { 2 - 5 } Morphology tests & Mean & SD & Mean & SD \\
\hline Roots & & & & \\
\hline Derivational morphemes & 7.70 & 1.62 & 7.73 & 1.66 \\
\hline Compounds & 7.54 & 1.40 & 7.60 & 1.00 \\
\hline Inflectional morphemes & 8.00 & 2.00 & 8.17 & 1.98 \\
\hline Total (\%) & 77,15 & & 77.67 & -- \\
\hline
\end{tabular}

Table 5 shows that the total pre-test mean score was almost the same as the post- test for the control group. They were $(\overline{\mathrm{x}}=77.15)$ and $(\overline{\mathrm{x}}=77.67)$ respectively. Similar to the whole group performance, the control group's scores at the different morphological awareness tasks were higher than $7 / 10$, exept scores at inflectional morphemes which were exactly $8 / 10$.

Matched-pair t-tests were conducted to check the performances of the control group on the morphological awareness pretest and posttest. First, the control group's performance on the roots pre-test $(\overline{\mathrm{x}}=7.54 \mathrm{~S} . \mathrm{D}=1.40)$ and post-test $(\overline{\mathrm{x}}=7.60 \mathrm{~S} . \mathrm{D}=1.00)$ reveals that students' scores improved slightly as it can be seen through the mean difference between the pre-test and the post- test $(\mathrm{MD}=0.06)$, with a $t(29)=0.09, p=0.84$. However, this $t_{\text {obs }}$ value did not exceed the $\mathrm{t}$ critical value of 1.69 . Consequently, we can conclude confidently that scores did not differ significantly from the pretest to the posttest, and that slight increase was due to chance. Actually, this may be explained by the absence of the treatment for the control group. Second, as far as the derivational morphemes test was concerned, Students' mean score between the pre-test $(\bar{x}=7.87, S . D=1.53)$ and the post-test $(\bar{x}=7.7, \quad$ S.D $=1.12)$ did not witness a significant improvement: $t(29)=0.03, p=0.94$. Once again, this insignificant improvement can be explained by the absence of the instructional treatment. Third, the comparison between the control group's performance in the compound-word pre-test $(\overline{\mathrm{x}}=7.62 \mathrm{~S} . \mathrm{D}=1.87)$ and post-test $(\bar{x}=7.57$ S.D $=2.03)$ reveals a regression in students' scores. Though this regression is not significant, it shows that the 
control group did not witness any improvement, which may be explained once again by the absence of the instructional treatment for the control group and may be the difficulty of the test itself.

Finally, the comparison between the control group's performance in the inflectional morphemes pre-test $(\overline{\mathrm{x}}=8.00$ S.D $=2.00)$ and post-test $(\overline{\mathrm{x}}=8.17$ S.D $=1.98)$ reveals that students' scores improved slightly. However, the mean difference between the pre- and the post- test $(\mathrm{MD}=0.17)$ was not significant at the 0.5 level. $t(29)=$ $0.16, p=0.74$. The following line charts illustrate the control group' mean performances on the pre- and post tests.

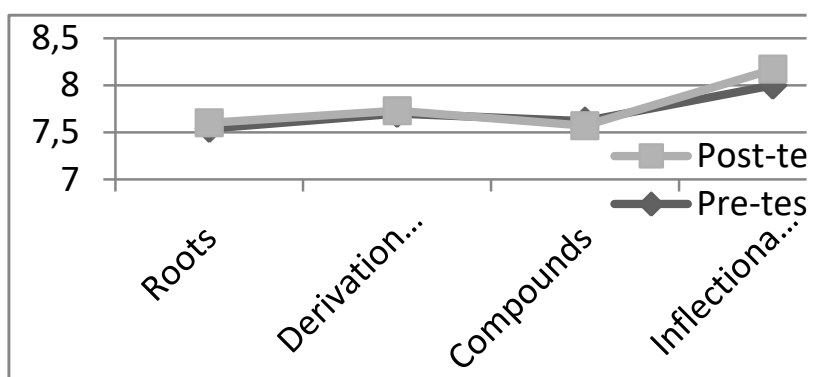

Fig. 3: Line charts showing the control group's mean scores on the pre and post morphological awareness tests

This graph better shows the consistent results of performances on the pre and post tests. In technical terminology, there is an insignificant "disordinal interaction" between the pretest and the posttest. That is to say, the results on the different morphology tests were almost the same with three insignificant improvements and one regression on compounds. Besides, the graph illustrates that the two lines of the chart overlap very much. This means that the control group scores on the pre and post tests are almost similar. The similarity of scores is an indication of the test-retest reliability of the morphology test. The next part of the analysis is devoted to the performances of the experimental group.

\subsection{The experimental group performances on the pre- and post morphology tests}

First, the comparison between the experimental group's performance on the roots pre-test $(\bar{x}=7.43 \mathrm{~S} . \mathrm{D}=1.45)$ and post-test $(\overline{\mathrm{x}}=7.9$ S.D=0.96) shown in Table 12 below reveals that students' scores improved as it can be seen through the mean difference between the pre-test and the post- test $(\mathrm{MD}=0.47)$. It was necessary to calculate the observed $t$ value to check the significance of this difference: $t_{o b s}=1.91$. In spite of this small $t_{o b s}$ value, it still exceeds the $t$ critical value of 1.69. Consequently, we can conclude confidently that the experimental group scores differ from the pretest to the posttest.

Table 6: The experimental group performances on the pre and post morphology tests $(N=30)$

\begin{tabular}{|l|l|c|c|c|}
\hline \multirow{2}{*}{$\begin{array}{c}\text { Test type } \\
\text { Morphology tests }\end{array}$} & \multicolumn{2}{c|}{ Pre Test } & \multicolumn{2}{c|}{ Post Test } \\
\cline { 2 - 5 } & Mean & SD & Mean & SD \\
\hline Roots & 7.43 & 1.45 & 7.9 & 0.96 \\
\hline Derivational morphemes & 7.87 & 1.53 & 7.7 & 1.12 \\
\hline Compounds & 8.07 & 1.53 & 8.63 & 1.71 \\
\hline Inflectional morphemes & 8.37 & 1.30 & 8.66 & 1.06 \\
\hline
\end{tabular}

Second, as far as the derivational morphemes test is concerned, there was a regression in the experimental students' mean score between the pre-test $(\bar{x}=7.87$, $\mathrm{S} . \mathrm{D}=1.53)$ and the post-test $(\overline{\mathrm{x}}=7.7, \mathrm{~S} . \mathrm{D}=1.12)$. Though this regression was not significant, it shows that the experimental group did not witness any improvement, which may question the effectiveness of the instructional treatment and the difficulty of the test itself.

Third, the comparison between the experimental group's performance on the compound-word pre-test ( $\overline{\mathrm{x}}=8.07 \mathrm{~S} . \mathrm{D}=$ 1.53) and post-test ( $\bar{x}=8.63 \quad S . D=1.71)$ reveals that students' scores improved as highlighted by the small improvement shown through the mean difference $(\mathrm{MD}=$ 0.56). This means that, post-test results of the experimental group were slightly better than those of the pre-test as confirmed by the t-test result: $t_{o b s}=1.99$. Obviously, we can conclude that the experimental group scores differ significantly from the pretest to the posttest because the $t_{o b s}$ value exceeds the t critical value.

Finally, the comparison between the experimental group's performance on the inflectional morphemes pre-test $(\overline{\mathrm{x}}=8.37$ S.D $=1.30)$ and post-test $(\overline{\mathrm{x}}=8.66$ S.D $=1.06)$ reveals that students' scores improved. However, the mean difference between the pre- and the post- test $(\mathrm{MD}=0.29)$ was not significant at the 0.5 level. $t(29)=1.18, p=0.27$. So, this small improvement does not provide insightful evidence of the effectiveness of the instructional treatment. The following graph summarizes the experimental group' mean performances on the pre- and post tests. 


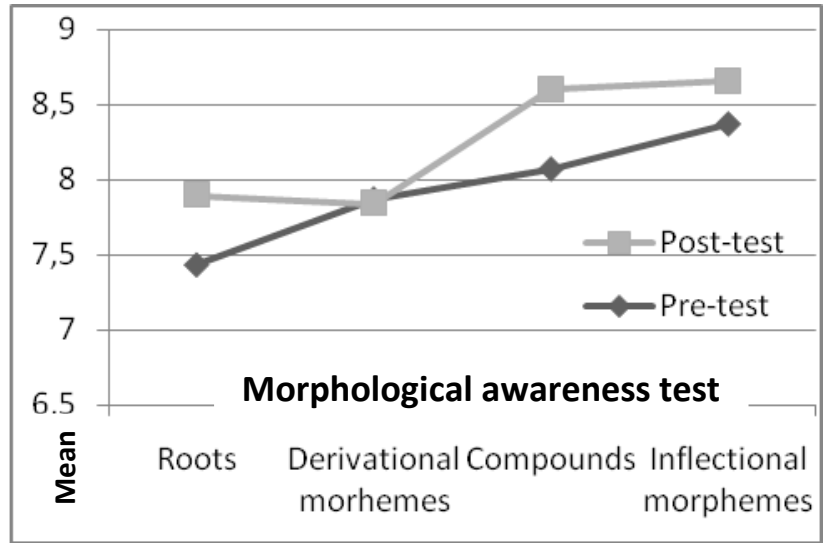

Fig. 4: Line charts showing the experimental students' mean scores on the pre and post morphological awareness tests

A significant "disordinal interaction" is obvious from this figure: the differences between means not only vary, but change order across the 4 levels leading the lines representing the pretest and posttest to cross. Three major facts can be concluded from these line charts. First, students' scores on roots, compounds, and inflectional morphemes witnessed a significant change. Second, performances on derivational morphemes remained the same on the pre- and post-test. Third, the participants performed best on inflectional morphemes. Concerning the first fact, this slight improvement of scores on the majority of the tasks may give an insightful evidence of the effectiveness of the treatment. As far as the second and the third remarks are concerned, they can be explained by the challenging nature of derivational morphemes and the relative easiness of inflectional morphemes (Koda, 2000; Singson, Mahony and Mann, 2000). Below are the groups' performances on morphological awareness pre-tests.

\subsection{Morphological Awareness and Receptive and Productive Vocabulary Knowledge}

The second research question investigated the relationship between English morphological awareness and vocabulary knowledge of the participants. Mean scores of the whole group (60participants) in the VLTs (receptive and productive) and the morphological awareness tasks were correlated using Pearson's product-moment to assess the strength of association between the tests. Besides, the performances of each group (experimental and control) in these tasks were correlated as well.

As far as the whole group is concerned, morphological awareness tasks correlated significantly with both the RVT and the PVT, although the strength of association was not high. Pearson's product-moment correlations were .42 and .32 at $p<.05$, with $\mathrm{r}_{\text {crit }}=0.25$ (see Table 7). The correlation of the morphological awareness test and RVT scores was comparatively higher compared to those of the morphological awareness test and the PVT results. The findings for the group as a whole reveal that there is a significant relationship between morphological awareness and vocabulary knowledge. This is supported by Chang et al. (2005) who pointed out that since this is a correlational study, the causal relationship among the two variables could not be predicted.

Furthermore, results reveal a different pattern of association between the two groups (Control and experimental). As shown in Table 7, the morphological awareness scores obtained by students in the control group reached statistical significance when correlated with the scores of their receptive and productive vocabulary tests. On the other hand, the experimental group scores on the morphological awareness test correlated significantly with their receptive and productive vocabulary scores than the control group. Also, the table shows that on the whole, the strengh of the relationship between the different correlations can be considered as moderate.

Table 7: Intercorrelations between the vocabulary language test and morphological awareness test

\begin{tabular}{|l|c|c|c|}
\hline \multirow{2}{*}{} & \multicolumn{3}{|c|}{ Morphological Awareness Test } \\
\cline { 2 - 4 } & Whole group & Control & Experimental \\
\hline $\begin{array}{l}\text { Receptive } \\
\text { Vocabulary } \\
\text { Test }\end{array}$ & 0.42 & 0.37 & 0.47 \\
\hline $\begin{array}{l}\text { Productive } \\
\text { Vocabulary } \\
\text { Test }\end{array}$ & 0.32 & 0.29 & 0.36 \\
\hline
\end{tabular}

Note. Correlation is significant at the .05 level (1-tailed

Results reveal that students' performance on the vocabulary language test correlated positively with the morphological awareness test. Also, results revealed that morphological awareness correlated positively with both receptive and productive vocabulary tests. A striking fact is that pearson's $r$ was insignificant for the control group in the productive vocabulary test. Regardless of these differences, the direction of the relationship is positive. Actually, this relationship can be best viewed via Henriksen's model: morphological awareness as part of the depth of knowledge continuum is related to the receptive-productive continuum. This means that, if a student's morphological awareness is high, his or her vocabulary knowledge is more likely to be high too. So, morphological awareness and vocabulary knowledge are 
both crucial subcomponents for the development of general linguistic knowledge.

Assuming that "large" effects are always more important than "small" or "medium" ones is unjustified. David Funder (2012) argued that correlation of .30 (commonly regarded as a quite modest correlation) can be considered in certain contexts as medium correlation coefficient. Similarly, some educational researchers have indicated that effect sizes around 0.20 are of policy interest when they are based on measures of academic achievement (Hedges \& Hedberg, 2007). For example, a study with an effect of 0.20, which at first glance, might be misinterpreted as a "small" effect if one automatically applies Cohen's original conventions, can be an important outcome in some research areas. So, the interpretation of the effect sizes has to be made in relation to the context of the research in question.

Three meaningful guidelines have been used in order to evaluate effect sizes in context. The first guideline is the source or the quality of the research itself. This means the association of the study to prior and to new findings. Secondly, it is important to make comparisons across similar research conditions (measurements, study design etc.) Finally, it is not only the magnitude of the effect that is important, but also its practical or clinical value must be considered. Clinical value reflects the extent to which there has been meaningful change in participants' lives.

In conclusion, based on these guidelines the relationship between morphological awareness and vocabulary knowledge in this study can be considered on the whole as moderate. As it was stated previously, an effect size by itself can mean almost anything. A "small" or a "moderate" effect size, as in this study, can be important and have practical value since small correlations are the most common correlations in the social and behavioral sciences. The reason for this is that, most variables are affected by numerous factors. Besides, it is important to keep in mind that a large correlation is not a correlation of 90. Correlations of this size are often between two different measures of the same variable. Such large correlations often indicate not a meaningful relationship between variables, but an artificial one (Kenny: 1987).

\section{CONCLUSION}

First, the results revealed that students' scores were higher at the receptive vocabulary tasks than the productive ones. Besides, the informants performed better on the 2000 word level at both the receptive and the productive vocabulary tests. Second, the results showed that the students exhibited an average overall morphological awareness of ISSN: 2456-7620 word formation rules. However, the participants performed better at the inflectional morphemes task than the other tasks. Third, the present study displayed that there was a significant correlation between morphological awareness and vocabulary size. Beck et al. (2002) argued that promoting learners' vocabulary knowledge as well as their morphological knowledge could be good predictors for academic success. That is to say, students would move from learning to read to reading to learn independently and become autonomous learners. Finally, results of the questionnaire show that students from the experimental group expressed their interest to study and use this method. Consequently, the introduction of morphological awareness raising as a vocabulary building strategy could be of much help for students to boost their vocabulary repertoire and therefore could be included in the curriculum.

\section{REFERENCES}

[1] Bear, D.R., Invernizzi, M., Tempelton, S., \& Johnston, F. (2008). Words Their Way: Word Study for phonics, vocabulary, and spelling instruction (4 $4^{\text {th }}$ edition). Upper Saddler River, NJ: Pearson Prentice Hall.

[2] Beck, I. L., McKeown, M. G., \& Kucan, L. (2002). Bringing words to life: robust vocabulary instruction. New York: Guilford Press.

[3] Carlisle, J. F \& Stone, C. A. (2003). The effect of morphological structure on children's reading derived words in English. In E. M. Assink, \& D. Sandra (Eds.), Reading complex words (27-51). New York: Kluwer Academic.

[4] Chang, C. M., Wagner, R. K., Muse, A \& Chow, H. S. (2005). The role of morphological awareness in children's vocabulary acquisition in English. Applied Psycholinguistics, 26, 415-435.

[5] Ellis, N. (1997). Vocabulary acquisition: word structure, collocation, word-class andmeaning. In N. Schmitt \& M. McCarthy (Eds.), Vocabulary: Description, acquisition andpedagogy (122-139).Cambridge:Cambridge University Press.

[6] Funder, D.C. (2012). Accurate personality judgment. Current Directions in Psychological Science, 21, 177-182.

[7] Graves, M.F. (2004). Teaching prefixes: as good as it gets. In J.F. Baumann \& E.J. Kame'enui (Eds.), Vocabulary instruction: Research to practice. New York: Guilford.

[8] Gordon, P. (1989). Levels of affixation in the acquisition of English morphology. Journal of Memory and Language, 28, 518- 520 .

[9] Hayashy, Y, \& Murphy, V.A. (2009). Morphological awareness and second language receptive and productive vocabulary knowledge in Japanese learners of English. International Conference on First and Second Languages: 
Exploring the Relationship in Pedagogy Related Contexts, Oxford, England.

[10] Hedges, L \& Hedberg, E.C. (2007). Intra-class correlation values for planning group-randomized trials in education. Educational Evaluation and Policy Analysis, 29: 60-87.

[11] Kenny, D. (1987).Statistics for the social and behavioral sciences. Boston: Little, Brown.

[12] Koda, K. (2000). Cross-linguistic variations in L2 morphological awareness. Applied Psycholinguistics, 21, 298- 319.

[13] Kuo, L. - J. \& Anderson, R. C. (2006). Morphological awareness and learning to read: A cross-language perspective. Educational Psychologist, 41, 161-180.

[14] Laufer, B., \& Nation, P. (1995). Vocabulary size and use: lexical richness in L2 written production. Applied Linguistics, 16 (3), 307- 322.

[15] Nagy, W. E., \& Anderson, R. C. (1984). How many words are there in printed school English? Reading Research Quarterly, 19 (3), 304-330.

[16] Nation, .P. (2001) Learning Vocabulary in Another Language. Cambridge: Cambridge University Press.

[17] O’Malley, J. M., \& Chamot, A. U. (1990). Learning strategies in second language acquisition. Cambridge: Cambridge University Press.

[18] Singson, M., Mahony, D., \& Mann, V. (2000). The relation between reading ability and morphological skills: evidence from derivational suffixes. Reading and Writing: An Interdisciplinary Journal, 21, 219- 252.

[19] Wang, M., Cheng, C., \& Chen, S. (2006). Contribution of morphological awareness to Chinese-English biliteracy acquisition. Journal of Educational Psychology, 98 (3), 542. 